Int. J. Morphol.,

32(1):112-118, 2014.

\title{
Application of a More Advanced Procedure in Defining Morphological Types
}

\author{
Aplicación de un Procedimiento Más Avanzado en la Definición de Tipos Morfológicos
}

\author{
Damjan Jaksic*; Ljubisa Lilic**; Stevo Popovic***; Radenko Matic* \& Slavko Molnar*
}

JAKSIC, D.; LILIC, L.; POPOVIC, S.; MATIC, R. \& MOLNAR, S. Application of a more advanced procedure in defining morphological types. Int. J. Morphol., 32(1):112-118, 2014.

SUMMARY: It is well known that the most evident differences in humans are those related to anthropometric characteristics, and that during continuous monitoring the relation between human behavior and human abilities concerning their anthropometric characteristics was observed. The aim of this study was to detect and define the morphological types with the use of slightly different and more advanced methodologies. The sample included 149 male subjects, first-year students of the Faculty of Sport and Physical Education in Novi Sad, using an anthropometric measurement technique. A total of 12 anthropometric measures, defined according to the fourdimensional morphological model was used. For all variables, basic descriptive statistics were calculated while student grouping was performed using taxonomic neural network - Intruder. Initial taxonomic classification of artificial entities by neural network Intruder accepted four clusters: endomorph or pyknic, ectomorph or leptosomic, astenomorph and gracile type. The results indicate that the identification and definition of morphological types with the use of a slightly different and more advanced procedure leads to better and earlier perception of certain characteristics which are necessary, both for the selection of specific sports, and in the prevention of various diseases and abnormalities in behavior and functioning.

KEY WORDS: Neural network; Intruder; Students; Anthropometry; Somatotypology.

\section{INTRODUCTION}

Throughout time it has been known that the most evident differences in humans were observed in anthropometric characteristics, and during continuous monitoring of these characteristics a relationship was observed between behavior and different abilities of humans with respect to their anthropometric characteristics. On the one hand, modern science has known the determination of constitutional types, which reflect a specific set of structuralmorphological, physiological-functional and psychological cognitive-conative characteristics of a person, differentiating them from others representing a broad guideline (MisigojDurakovic, 2008), while on the other hand, in determination of morphological types and the search for differences between them, emphasis is placed only on anthropometric measures and morphological characteristics.

There is great interest in the identification of both. It has been reported that during the time of Hippocrates, even he observed type-differentiating in people. Kretschmer's research (Kretschmer, 1926, 1955), then Conrad's (1963) are considered to be the beginnings of more contemporary definition of morphological types. They based their findings on the etiology of the formation of a constitutional type. A somewhat different approach was provided by Sheldon et al. (1940, 1954), which defined a somatotype determined as the quantification of three embryonic components which they originally called pyknosomic, somatosomic and leptosomic, and later the endoderm, mesoderm and ectoderm. In this way, Sheldon et al. (1940, 1954), proposed a classification according to the dominance of one of three embryonic components. The biggest drawback of the classification by Sheldon was reflected in the segment of duration of morphological types. After determining the morphological type there is no allowance for a potential change over time, and is based on the belief that the increase and decrease of fat differences does not change somatotype,

\footnotetext{
* University of Novi Sad, Faculty of Sport and Physical Education, Novi Sad, Serbia.

** University of Pristina, Faculty for Sport and Physical Education, Leposavic, Serbia.

*** University of Montenegro, Faculty of Sport and Physical Education, Niksic, Montenegro.
} 
because it does not lead to significant changes in any of the dimensions, except the place of stocking. Then Sheldon adds that 4-4-4 somatotype is not changed by eating, or any other habits to 4-4-3, but there are only thick or thin 4-4-4. Nowadays, most authors recognize the variability of somatotype, therefore Sheldon's thesis of the invariability of somatotype breaks down. In the Balkans, pathologist Saltykow and Slovenian anthropologist Skerlj were especially recognized, the latter having published about 15 books and over 160 articles presenting the results of his work mainly dealing with body physiques and body composition. Particularly noteworthy is his work with Brozek, a professor at the University of Minnesota, where they explained the dynamics of the formation of fatty deposits during aging in both sexes (Tomazo-Ravnik, 1998). The team of researchers around Momirovic', have contributed immensely in this area. They provided a number of recommendations and proposed new algorithms, which have practical implementation only in defining the morpho-typology. Recently, the most relevant choice for defining somatotype is the process by Carter (1970, 1984a, 1984b), especially by Carter \& Heath (1992), who listed recommendations and formulas for identification of the three main morphological types, but also defined intermediate types based on the results obtained by application of the formulas. This is a major advantage over previous procedures, and is widely noted in current literature.

The goal of the present study was to obtain and define the morphological types on the sample of students of Faculty of sports and physical education, with the implementation of different, more advanced and mathematically current methodology for their identification.

\section{MATERIAL AND METHOD}

The studied sample included 149 male subjects, firstyear students of the Faculty of Sport and Physical Education in Novi Sad. The average age of the subjects was 20.15 $( \pm 0.83)$ decimal years.

For data collection we used the anthropometric measurement technique. A total of 12 anthropometric measures were carried out, which, according to four-dimensional morphological model, defined the longitudinal and transversal dimension of the skeleton; subsequently we measured body volume and weight and subcutaneous adipose tissue. The following measures were applied: for evaluation of Longitudinal skeleton dimension: Body height, Arm length and Leg length, for Transversal evaluation of skeleton dimension: Ankle diameter, Knee diameter and Pelvis width, for evaluation of Body volume and weight: Body weight,
Chest girth and Upperarm girth and for Subcutaneous adipose tissue evaluation: Subscapular skinfold, Triceps skinfold and Abdominal skinfold. Measurement of anthropometric characteristics was conducted at the Faculty of Sport and Physical Education in Novi Sad according to the standards of the International Biological Program (IBP) (Lohman et al., 1988), following basic rules and principles relating to the choice of parameters, standard conditions and measurement techniques, as well as standard measuring instruments calibrated by a qualified and trained measurer prior to measurement. In addition, all subjects were selected during their enrollment at the faculty, after passing medical examinations during which the doctor determined that subjects did not exhibit somatoscopic-functional medical conditions. On the testing day subjects felt comfortable, they were dressed in shorts and t-shirts and the equipment was adapted for convenient and simple measurement method.

Basic descriptive statistics were calculated for all variables and subjects were divided using a more advanced procedure - taxonomic neural network Intruder (Momirovic, 2001). The point of this neural network is an iterative application of Lebart's adaptive multi-layer perceptron to form the indicator matrix (Lebart, 1998), which is most similar to the standardized matrix of input data by the leastsquares criterion. This network is supplied with preprocessor, which forms an initial indicator matrix by searching the extreme values on the edge of the hyperellipsoid formed by orthoblique transformation of the main components of standardized data matrix. Number of these components, and thus the number of taxons is initially determined based on the PB criterion (Stalec \& Momirovic, 1971), while the final classification is done using the Fisherian's discriminant analysis method. The program is written in the Matrix programming language, because of the possibility of using in standard SPSS environment. The differences among taxons for each analyzed variable were determined by univariate analysis of variance (ANOVA) resulting in a more accurate definition of morphological types.

\section{RESULTS AND DISCUSSION}

Table I shows the basic descriptive statistics analysis that was conducted to evaluate the appropriateness of further consideration of the obtained data and determination of the directions and methodological priorities of their processing.

By examining the same, it is evident that the sample of respondents was fairly homogeneous in terms of some variables used for evaluation of longitudinal and transversal dimensionality of the skeleton, and also in volume and 
Table I. Basic Descriptive Statistics.

\begin{tabular}{lccccccc}
\hline Variable & Mean & SD & Min & Max & CV & SKE & KUR \\
\hline Body height (mm) & 1816.26 & 62.99 & 1670 & 1975 & 3.46 & 0.05 & -0.62 \\
Arm length (mm) & 798.32 & 36.17 & 717 & 899 & 4.53 & 0.03 & -0.30 \\
Leg length (mm) & 1022.36 & 44.14 & 894 & 1134 & 4.31 & -0.06 & -0.01 \\
Ankle diameter (mm) & 70.99 & 3.89 & 62 & 85 & 5.48 & 0.69 & 1.13 \\
Knee diameter (mm) & 100.22 & 4.32 & 91 & 113 & 4.31 & 0.16 & -0.20 \\
Pelvis width (mm) & 286.68 & 16.60 & 255 & 345 & 5.79 & 0.50 & 0.53 \\
Body weight (kg) & 77.90 & 9.33 & 54.6 & 123.8 & 11.97 & 0.89 & 3.22 \\
Chest girth (cm) & 96.71 & 5.44 & 80 & 118 & 5.62 & 0.39 & 1.76 \\
Upperarm girth (cm) & 28.13 & 2.61 & 22 & 36 & 7.77 & 0.67 & 0.89 \\
Subscapular skinfold (mm) & 118.56 & 33.33 & 68 & 254 & 26.78 & 1.37 & 2.77 \\
Triceps skinfold (mm) & 91.02 & 32.10 & 28 & 190 & 35.26 & 0.60 & 0.09 \\
Abdominal skinfold (mm) & 131.31 & 51.24 & 52 & 300 & 39.02 & 0.69 & -0.06 \\
\hline
\end{tabular}

$\mathrm{SD}=$ standard deviation; $\mathrm{Min}=$ minimal result $\mathrm{Max}=$ maximal result $\mathrm{CV}=$ coefficient of variation; $\mathrm{SKE}=$ skewness; KUR $=$ kurtosis.

Table II. Initial Classification of Entities.

\begin{tabular}{ccccc}
\hline & g1 & g2 & g3 & g4 \\
\hline g1 & 34 & 0 & 0 & 2 \\
g2 & 1 & 34 & 2 & 1 \\
g3 & 0 & 2 & 32 & 6 \\
g4 & 1 & 1 & 1 & 32 \\
\hline g= group & & & &
\end{tabular}

Table III. Discriminative Coefficients (DC).

\begin{tabular}{lcccc}
\hline Variable & DC1 & DC2 & DC3 & DC4 \\
\hline Body height & 0.14 & 0.66 & 0.54 & -0.38 \\
Arm length & -0.08 & -0.34 & 0.87 & 0.50 \\
Leg length & -0.43 & 0.40 & -0.20 & 0.24 \\
Ankle diameter & 0.38 & 0.11 & 0.21 & -0.70 \\
Knee diameter & 0.00 & 0.45 & 0.28 & -0.75 \\
Pel vis width & -0.03 & 0.20 & -0.03 & -0.14 \\
Body weight & -0.14 & -0.68 & 0.05 & 0.78 \\
Chest girth & 0.63 & 0.60 & -0.29 & 0.08 \\
Upperarm girth & -0.20 & 0.45 & -0.28 & 0.02 \\
Subsca pular skinfold & 0.32 & -0.22 & 0.11 & -0.20 \\
Triceps skinfold & 0.51 & -0.22 & 0.29 & -0.57 \\
Abdominal skinfold & -0.33 & -0.47 & 0.20 & 0.59 \\
\hline
\end{tabular}

this network and PB criterion four taxons were adopted.

In the same table, it should be noted that some subjects were not clearly classified in any one of the taxons, but their structures overlap with the structures of several taxons. The algorithm in the initial stage considered that in this set there are four distinct taxons, and such large number of taxons is retained until the end. If it was intended for clear identification of taxons to be completely implemented until the very end, algorithm of taxonomic neural network is designed in such a manner so the process of "learning" of the algorithm of the taxonomic neural network was introduced, thus allowing further classification. After seven learning attempts algorithm stabilized, and subsequently carried out a re-classification. This way, we obtained more accurate and more complete results of classification (Table III). weight of the body. However, it is evident that there are differences in terms of the variables used for evaluation of the subcutaneous adipose tissue, where there is a significant deviation from the mean, as indicated by the variation coefficient and the standard deviation.

A reduction of complete results of the analysis due to size was necessary, and, accordingly only the most important results of the analysis are shown below. Table II shows the results obtained by the initial classification of the entities by artificial taxonomic network Intruder. Based on
Because, in some cases, the classification was performed solely on the basis of neural network, and thus, does not give a clear identification of the structure, the algorithm was added with the Fisherian's discriminant analysis, which further verifies the classification and which is derived in the full space of the variables. This was done because the analysis in the intra-taxonomic space would probably produce unstable results. In the following tables (Tables IV, V and VI) the results of discriminant analysis which clearly shows what are the morphological characteristics of the four morphological types. 
Table IV. Structure (F) And Pattern (A) Of Discriminative Functions.

\begin{tabular}{lcccccccc}
\hline \multirow{2}{*}{ Variable } & \multicolumn{4}{c}{ Structure } & \multicolumn{4}{c}{ Pattern } \\
\cline { 2 - 9 } & F1 & F2 & F3 & F4 & A1 & A2 & A3 & A4 \\
\hline Body height & -0.58 & 0.66 & 0.08 & -0.18 & -0.42 & 0.47 & 0.05 & -0.12 \\
Arm length & -0.74 & 0.50 & 0.20 & 0.01 & -0.55 & 0.34 & 0.16 & 0.02 \\
Leg length & -0.67 & 0.59 & -0.05 & 0.10 & -0.49 & 0.41 & -0.03 & 0.08 \\
Ankle diameter & 0.06 & 0.45 & -0.02 & -0.51 & 0.07 & 0.34 & -0.03 & -0.39 \\
Knee diameter & -0.07 & 0.52 & 0.04 & -0.51 & -0.02 & 0.39 & 0.00 & -0.38 \\
Pelvis width & -0.27 & 0.51 & 0.06 & -0.32 & -0.18 & 0.37 & 0.03 & -0.23 \\
Body weight & 0.06 & 0.31 & -0.31 & -0.07 & 0.06 & 0.24 & -0.24 & -0.06 \\
Chest girth & 0.25 & 0.35 & -0.63 & 0.01 & 0.21 & 0.27 & -0.49 & -0.01 \\
Upperarm girth & 0.30 & 0.20 & -0.58 & 0.07 & 0.25 & 0.17 & -0.45 & 0.02 \\
Subscapular skinfold & 0.33 & -0.27 & -0.15 & 0.10 & 0.24 & -0.19 & -0.11 & 0.07 \\
Triceps skinfold & 0.35 & -0.33 & 0.16 & -0.16 & 0.25 & -0.23 & 0.11 & -0.12 \\
Abdominal skinfold & 0.27 & -0.42 & -0.06 & 0.21 & 0.19 & -0.30 & -0.03 & 0.15 \\
\hline
\end{tabular}

Table V. Contingency classification formed by neural network and Fisherian method of discriminative analysis.

\begin{tabular}{lcccc}
\hline & g1 & g2 & g3 & g4 \\
\hline g1 & 36 & 0 & 0 & 0 \\
g2 & 0 & 38 & 0 & 0 \\
g3 & 0 & 0 & 38 & 0 \\
g4 & 0 & 0 & 0 & 37 \\
\hline g= group & & & &
\end{tabular}

Table VI Sample Size And Predicted Classification.

\begin{tabular}{lccc}
\hline & Number & Prediction & Difference \\
\hline g1 & 36 & 36 & 0 \\
g2 & 38 & 38 & 0 \\
g3 & 38 & 38 & 0 \\
g4 & 37 & 37 & 0 \\
\hline
\end{tabular}

$\mathrm{g}=$ group

From the previous tables it can be seen that with the additional checking of classification there were no eventual reductions. It is precisely this kind of classification, obtained after the learning process of neural networks, which was finally adopted with an efficiency ratio of $100 \%$. With previously reported values in the tables, and the values in the following plots (Fig. 1), it was possible to start with the defining of taxons.

In accordance with the above, the first taxon is characterized by extremely low values in the domain of all measures of longitudinal dimensionality, higher values in the domain of muscle volume and subcutaneous adipose tissue, and the average values of the circular variables. This taxon could be defined as: endomorphic or pyknic type, depending on classification. Other taxon is predominantly described by pronounced longitudinality and transversality, low levels of subcutaneous fat accumulated in the abdomen, while the values of other variables are slightly higher than the average, therefore this taxon could be defined as: ectomorphic or leptosomic type. Characteristics of third taxon are reduced values of chest girth and upperarm girth and slightly lower body weight than average. All other variables displayed values in the range of average. This taxon is therefore comprised of insufficiently developed persons, with weak muscles, so this phenomenon could be defined as asthenia, and a taxon as: astenomorphic type. While the fourth taxon is mostly characterized by significantly lower values than average in terms of Ankle diameter, Knee diameter, and Pelvic width to a lesser extent, while all other variables are within average. This taxon could be defined as: gracilis type.

Relatively new research which used artificial neural network to identify morphological types are researched by Momirovic et al. (2003), and Prot et al. (2003), in which two different neural networks are used: Simtax neural network in the first and taxonomic neural network Triathlon in the second case. Both of these neural networks are conceptually and algorithmic very similar to neural network Intruder, which was used in this study. However, in a similar sample these neural networks extracted different results. Simtax identified three types, namely: astenomorphic, stenomorphic and pyknomorphic type, while the neural network Triathlon identified four types: astenomorphic, stenomorphic, disharmonic and leptomorphic type. It is evident that the disharmonic type is identified for the first time, while the other types are present in almost all-previous research.

As most recent studies conducted around the world are based on the Heath-Carter's somatotypology, it was necessary to the extent possible, to compare the results of this research with works which treated somatotypology 

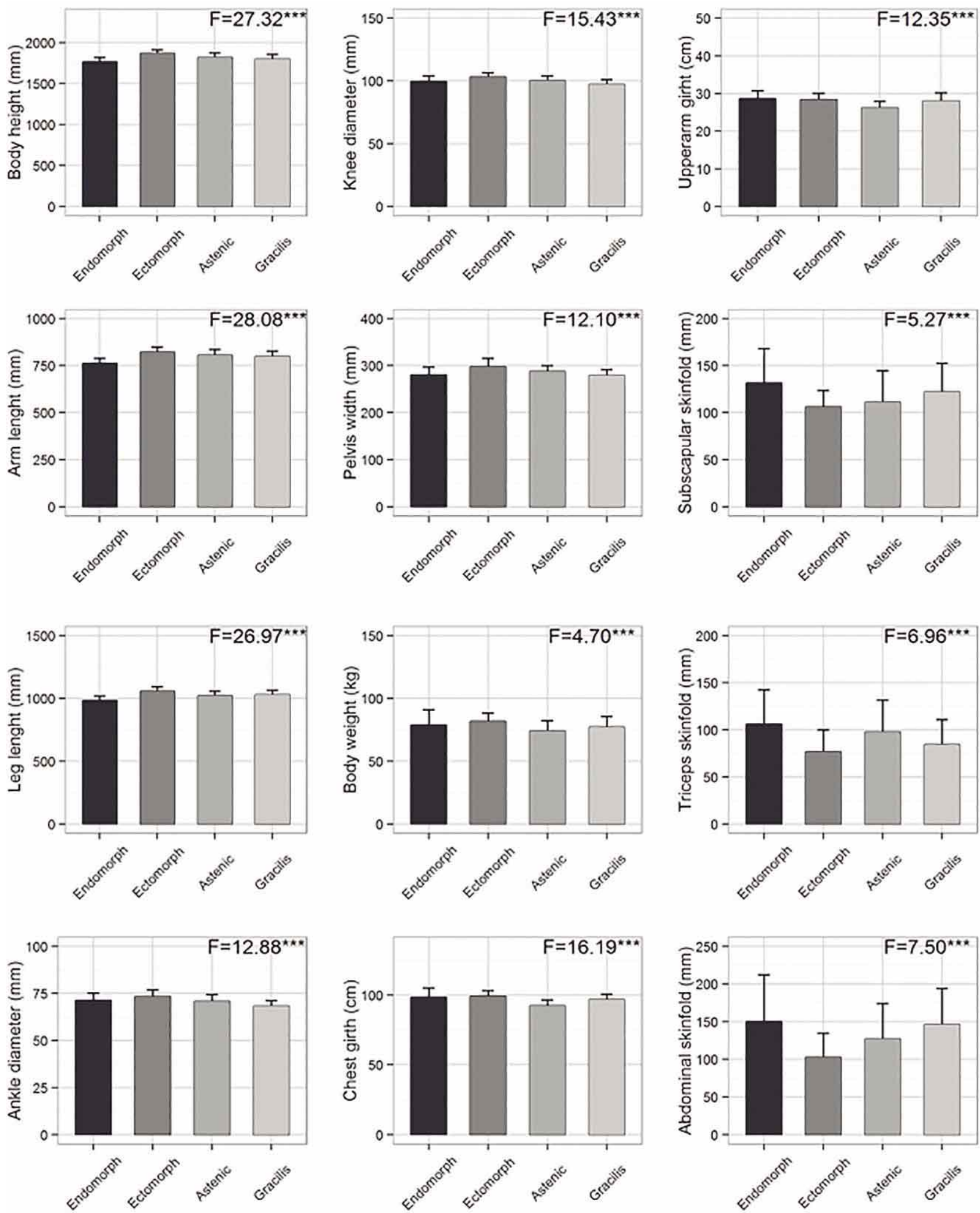

Fig. 1. Differences between distinguished morphological types. 
problem in this way. Comparing the results obtained in this research to results concerning medical students from Bulgaria (Radev et al., 1985) it is noteworthy that the dominant group among them was endomorphicmesomorphic, but also distinct and somatotypic groups were isolated and obesity was more pronounced. The authors then note that it is necessary to pay attention to this problem, and in this research this problem was pointed to as the endomorphic group was quantitatively most pronounced. The dominant somatotype of Indonesian medical students is 3-5-4 (Rahmawati et al., 2007), and they can be categorized as an ecto-mesomorphic. Although their longitudinal dimensions are far below the average longitudinal dimensions of student of sport and physical education (165.6 vs. 181.6), the relationships between their dimensions indicate a certain ectomorphy, which is their subdominant feature. However, the closest to Novi Sad students are students from the University of Madrid, whose somatotype is almost identical and shows a certain connection with motor tests (Fuster et al., 1998). Related to this is the study by Jaksic \& Cvetkovic (2009) where some causal relationship between the morphological type and motor abilities was also found, which indirectly leads to success in a particular sport. For this reason, each sports discipline has a dominant morphological type that is better suited for successful results. This is supported by a conside- rable number of studies that attempted to determine what somatotype is the best suited to a positive outcome in a particular sports discipline. However, there is extensive literature wherein the somatotype is associated with various diseases, and also to determine whether there is a correlation between certain diseases and of morphological type.

The results obtained generally show that the identification and definition of morphological types with the use of a slightly different and more advanced methodologies in defining them, lead to better and more timely identification of certain morphological characteristics of both the students, and the general human population. The application of neural networks, data mining and other advanced statistical procedures in recent years have taken primacy in the world in a variety of areas, ranging from biomedicine, sports science, engineering, geology and so on. The practical applicability of this particular work could be reflected in the application of these and other procedures for the selection in certain sports, which is addressed in many papers (Toriola et al., 1985; Orvanová, 1990) or in the prevention, determination of risk groups and similarly with certain diseases (Singh, 2007; Catell \& Metzner, 1993). We believe that this is only initial research, and that subsequent papers should follow one of the stated directions.

JAKSIC, D.; LILIC, L.; POPOVIC, S.; MATIC, R. \& MOLNAR, S. Aplicación de un procedimiento más avanzado en la definición de tipos morfológicos. Int. J. Morphol., 32(1):112-118, 2014.

RESUMEN: Es bien sabido que las diferencias más evidentes en los seres humanos son aquellas relacionadas con las características antropométricas, lo cual fue observado durante el monitoreo continuo de la relación entre el comportamiento humano y las capacidades humanas. El objetivo de este estudio fue detectar y definir los tipos morfológicos con el uso de metodologías diferentes y más avanzadas. La muestra incluyó 149 sujetos hombres, estudiantes de primer año de la Facultad de Educación Física y Deportiva en Novi Sad, utilizando una técnica de medición antropométrica. Utilizamos un total de 12 medidas antropométricas, que se definieron de acuerdo con el modelo morfológico de cuatro dimensiones. Para todas las variables se calcularon los estadísticos descriptivos básicos, mientras que la agrupación estudiantil se realizó a través de red neuronal - Intruder. Para la clasificación taxonómica inicial de entidades artificiales por red neuronal Intruder se aceptaron cuatro grupos: endomorfo o pícnico, ectomorfo o leptosomo, astenomorfo y tipo grácil. Los resultados indican que la identificación y definición de los tipos morfológicos con el uso de un procedimiento algo diferente y más avanzado conduce a una mejor percepción de ciertas características que son necesarias, tanto para la selección de deportes específicos, como para la prevención de diversas enfermedades y alteraciones en el comportamiento y funcionamiento.

PALABRAS CLAVE: Red Neural; Intruder; Estudiantes; Antropometría; Tipología somática.

\section{REFERENCES}

Carter, J. E. L. Physical structure of olympic athletes. Part II: Kinanthropometry of Olympic Athletes. Medicine and Sport Science. New York, Basel, Karger, 1984a.

Carter, J. E. L. Somatotypes of olympic athletes from 1948 to 1976. In: Carter, J. E. L. (Ed.). Physical Structure of Olympic Athletes. Part II. Kinanthropometry of Olympic Athletes. Basel, Karger, 1984b. pp.80-109.

Carter, J. E. L. The somatotypes of athletes--a review. Hum. Biol., 42(2):535-69, 1970.

Carter, J. E. L. \& Heath, B. A. Somatotyping - development and applications. Cambridge, Cambridge University Press, 1992. 
Catell, P. \& Metzner, R. Associations among somatotype, temperament and selfactualization. Psychol. Rep., 72(3 Pt. 2):1165-6, 1993.

Conard, K. Constitutional types. Berlin, Göttingen, Heidelberg, Springer-Verlag, 1963.

Fuster, V.; Jerez, A. \& Ortega, A. Somatotype and physical performance in a sample of university students from Madrid. Int. J. Anthropol., 13(2):149-58, 1998.

Jaksic, D. \& Cvetkovic, M. Neural network analysis of somatotype differences among males related to the manifestation of motor abilities. Acta Kinesiol., 3(1):106-12, 2009.

Kretschmer, E. Constitution types in healthy people. Dtsch. Med. Wschr., 20-2, 1926.

Kretschmer, E. Physique and character. Berlin, Göttingen, Heidelberg, Springer, 1955.

Lebart, L. Correspodence analysis, discrimination and neural networks. In Hayashi, C.; Yajima, K.; Bock, H.; Ohsumi, N.; Tanaka, Y. \& Baba, Y. (Eds.). Data science, classification, and related methods. Tokyo, Springer, 1998.

Lohman, T. G.; Roche, A. F. \& Martorell, R. Anthropometric standardization reference manual. Chicago, Human Kinetics Books, 1988.

Misigoj-Durakovic, M. Kinanthropology. Biological aspects of physical exercise. Zagreb, Faculty of Kinesiology, 2008.

Momirovic, K. Automatic classification by neural networks. Technical Report, Belgrade, Institute of criminological and sociological research, 2001.

Momirovic, K.; Hosek, A.; Prot, F. \& Bosnar, K. About the morphological types of young adult males. Glas. Antropol. Drus. Srb., 38:29-45, 2003.

Orvanová, E. Somatotypes of weight lifters. J. Sport Sci., 8(2):11937, 1990.

Prot, F.; Bosnar, K.; Hošek, A. \& Momirovic', K. Application of neural networks in the identification of morphological types. In: Momirovic, K. \& Popovic, D. A. (Eds.). The design and application of taxonomic neural networks. Leposavic', University of Pris tina, Center for Multidisciplinary Research of the Faculty of Physical Education, 2003. pp.245-54.

Radev, V.; Khandzhiev, S. \& Kostadinov, D. The somatotype and fatty body weight of medical students. Vutr. Boles., 24(2):714, 1985.

Rahmawati, N. T.; Budiharjo, S. \& Ashizawa, K. Somatotypes of young male athletes and non-athlete students in Yogyakarta, Indonesia. Anthropol. Sci., 115(1):1-7, 2007.
Sheldon, W. H.; Dupertuis, C. W. \& McDermott, E. Atlas of man. New York, Harper and Brothers, 1954.

Sheldon, W. H.; Stevens, S. S. \& Tucker, W. B. The varieties of human physique. New York, Harper and Brothers, 1940.

Singh, S. P. Somatotype and disease - A review. In: Bhasin, V. \& Bhasin, M. K. (Eds.). Anthropology Today: Trends, Scope and Applications. Kamla, Raj Enterprises, 2007.

Stalec, J. \& Momirovic, K. The total amount of valid variance as the basis of the criterion for determining the number of significant principal components. Kinesiology, 1(1):79-93, 1971.

Tomazo-Ravnik, T. Studies of body composition in Slovenia. Coll. Antropol., 22(2):403-9, 1998.

Toriola, A. L.; Salokun, S. O. \& Mathur, D. N. Somatotype characteristics of male sprinters, basketball, soccer, and field hockey players. Int. J. Sports Med., 6(6):344-6, 1985.

Correspondence to:

Damjan Jaksic, MSc.

University of Novi Sad

Faculty of Sport and Physical Education

Lovc'enska str. 16, 21000 Novi Sad

SERBIA

Tel: +381638280546

Fax: +38121450199

Email: jaksicd@uns.ac.rs

Received: 13-07-2013

Accepted: 16-12-2013 